Stefan Thomas, Piet Boonekamp, Harry Vreuls, Jean-Sébastien Broc, Didier Bosseboeuf, Bruno Lapillonne, Nicola Labanca

\title{
How to measure the overall energy savings linked to policies and energy services at the national level?
}

Originally published as:

Stefan Thomas, Piet Boonekamp, Harry Vreuls, Jean-Sébastien Broc, Didier Bosseboeuf, Bruno Lapillonne, Nicola Labanca (2012):

How to measure the overall energy savings linked to policies and energy services at the national level?

In: Energy efficiency, 5, 1, pp. 19-35

DOI: $10.1007 / \mathrm{s} 12053-011-9122-x$

The final publication is available at www.springerlink.com 
Stefan Thomas ${ }^{a,{ }^{,}}$, Piet Boonekamp ${ }^{\mathrm{b}}$, Harry Vreuls ${ }^{\mathrm{c}}$, JeanSébastien Broc ${ }^{d}$, Didier Bosseboeuf ${ }^{e}$, Bruno Lapillonne, Nicola Labanca ${ }^{g}$

\section{How to measure the overall energy savings linked to policies and energy services at the national level?}

a, ${ }^{*}$ S. Thomas (author for correspondence), Wuppertal Institute for Climate, Environment and Energy, Döppersberg 19, 42103 Wuppertal, Germany, e-mail: stefan.thomas@wupperinst.org

b P. Boonekamp, Energy research Centre of the Netherlands (ECN), 1755 LE Petten, Westerduinweg 3, The Netherlands, e-mail: boonekamp@ecn.nl

${ }^{\mathrm{C}}$ H. Vreuls, NL Agency, Swentiboldstraat 21, 6137 AE Sittard, The Netherlands, e-mail: harry.vreuls@agentschapnl.nl

d J.-S. Broc, Ecole des Mines de Nantes, GEPEA UMR CNRS 6144, 4 rue Alfred Kastler, BP 20722, 44307 Nantes Cedex 03, France, e-mail: Jean-sebastien.Broc@emn.fr

e D. Bosseboeuf, Agence de l'environnement et de la maitrise de l'energie (ADEME),

27, Rue Louis Vicat, 75737 Paris Cedex 15, France, e-mail: didier.bosseboeuf@ademe.fr

${ }^{f}$ B. Lapillonne, ENERDATA SAS, 47 Avenue Alsace Lorraine, 38000 Grenoble, e-mail: bruno.lapillonne@enerdata.net

9 N. Labanca, Politecnico di Milano Dipartimento di Energia (eERG), Via Lambruschini n. 4, 20156 Milan, Italy, e-mail: nicola.labanca@polimi.it 


\title{
How to measure the overall energy savings linked to policies and energy services at the national level?
}

\begin{abstract}
The Energy End-use Efficiency and Energy Services Directive (ESD) of the European Union (EU) requires the Member States to define and attain an overall target of at least $9 \%$ annual energy savings between 2008 and 2016. Even if this target is indicative, this is the first international framework mandating countries to report on their energy savings results and proove achievement of their targets. The Directive thus also required the development of harmonised calculation methods that can be used by Member States for this proof and reporting.

Existing literature covers most of the usual issues related to energy savings evaluation, but mostly looking at single, given energy efficiency programmes or policies. The evaluation objective for the ESD implementation is different, as it aims at accounting for the whole energy savings achieved in a country. Moreover, one of the main difficulties is the diversity in history and experience on this topic among the Member States.

In this context, the European project EMEEES has worked out an integrated system of bottom-up and top-down methods for the measurement of energy savings. The paper presents the overview of its final results. The proposals, inter alia, include 20 bottom-up and 14 top-down case applications of general evaluation methods. They enable more than $90 \%$ of the potential energy savings to be measured and reported. They were used as a starting point by the European Commission to develop the methods recently recommended to the Member States

Furthermore, the paper briefly discusses the importance of the quantity to be measured - all or additional energy savings and the effect of measures implemented before the entering into force of the ESD ('early action'), and what this meant for the methods to be developed. It compares the main elements of calculation needed to ensure consistent results between bottom-up and top-down methods at the overall national level.

Finally, general conclusions are drawn about what could be the next steps in developing an evaluation system that enables a high degree of comparability of results between different countries.
\end{abstract}

\section{Introduction}

The Energy End-use Efficiency and Energy Services Directive (ESD) of the European Union (EU) requires the Member States to define and attain an overall target of at least $9 \%$ annual energy savings between 2008 and 2016. Even if this target is indicative, this is the first international framework mandating countries to report on their energy savings results and proove obtainment of their targets. The Directive thus also required the development of harmonised calculation methods that can be used by Member States for this proof and reporting.

Existing literature (e.g., CPUC 2006, EVO 2010, SRCI et al. 2001, TecMarket Works et al. 2004, Vreuls et al. 2005, Vine 2008) covers most of the usual issues related to energy savings evaluation. But mostly from a theoretical point of view, and looking at single, given energy efficiency programmes or policies. The evaluation objective for the ESD implementation is different, as it aims at accounting for the whole energy savings achieved in a country, not necessarily making the link with individual programmes or policies. Moreover, one of the main difficulties is the diversity in history and experience on this topic among the Member States. Indeed, this had prevented the Member States and the European Commission from agreeing on clear evaluation rules when the ESD text was decided.

Therefore, the constitution of a regulatory Committee of the Member States (hereafter named ESD Committee) has been included in the Directive to assist the European Commission, i.a., in the task of elaborating common and harmonised methods for the evaluation of energy savings. Due to the difficulties related to this task, the Commission also needed support from independent experts.

In this context, from 2006 to 2009, the European project "Evaluation and Monitoring for the EU Directive on Energy End-Use Efficiency and Energy Services" (EMEEES), with 21 partners and co-ordinated by the Wuppertal Institute, has worked out an integrated system of bottom-up and top-down methods for the measurement of energy savings induced by energy services and other energy efficiency improvement (EEI) measures. The project partners were able to bring strong experience in evaluation methodology and practice as well as different perspectives to the consortium. They included energy agencies, a ministry, two energy companies, and several research institutes and consultancies. This group thus gathered feedback and knowledge ranging from field experiences to academic work.

As said above, the unique feature of this project's task was the focus on the measurement of overall energy savings at the national level due to the complete portfolio of national, sub-national, but also EU-wide policies and measures, and even commercial energy services. In addition, the evaluation results need to be comparable between the EU Member States, so the methods need to be harmonised.

This paper presents the overview of the final results on the methods developed by the EMEEES project, including the most important principles and examples of application for bottom-up and top-down calculation. The project developed proposals that were used as a starting point by the European Commission to develop the set of methods recently recommended to the Member States. The proposals, inter alia, include a set of 20 bottom-up and 14 top-down evaluation case applications of 
general evaluation methods. These include proposals for harmonised default values for calculating unitary energy savings at the end-use level for most of the bottom-up methods. The methods and case applications developed by EMEEES are thus harmonised between Member States to the extent possible and enable more than $90 \%$ of the potential energy savings to be measured and reported. They can be found at www.evaluate-energy-savings.eu.

As there are important unclear points in the ESD text, the paper starts with a brief discussion of the importance of the quantity to be measured - all or additional energy savings - and the effect of measures implemented before the entering into force of the ESD ('early action'), and what this meant for the methods to be developed. The next section of the paper briefly presents the basics of the bottom-up and top-down calculation methods used, followed by a section on what can be done to harmonise calculation results and reporting between Member States. The paper then compares the main elements of calculation needed to ensure consistent results between bottom-up and top-down methods at the overall national level and presents the applicability of the methods developed by EMEEES in the EU Member States. It also includes results from one of the field tests of the methods in Italy. Details of the field tests in France can be found in (Broc et al. 2010).

Finally, general conclusions are drawn about what could be the next steps in developing an evaluation system that enables a high degree of comparability of results between different countries.

\section{The Importance of Measurement for the Effectiveness of the ESD}

The primary objective of the ESD is to achieve at least $9 \%$ of annual energy savings ${ }^{1}$ across the EU by inducing energy efficiency improvement measures and stimulating the energy services markets. Member States need to measure and prove the savings they achieved. But how much energy savings will these $9 \%$ really be? Will they contribute to the 'objective of saving $20 \%$ of the EU's energy consumption compared to projections by 2020 ' as stated by the European Council on 8/9 March 2007? The ESD does not explicitly mention that the energy efficiency improvement measures and the resulting energy savings shall be additional to the so-called autonomous savings ${ }^{2}$ that energy consumers, investors, or other market actors would have achieved by themselves anyway. However, the ESD energy savings will need to be additional to autonomous savings, if the EU is to attain the objective of saving $20 \%$ of the EU's energy consumption compared to projections - hence, additional savings - by 2020. This is the case, although the two targets are not directly comparable, since the ESD target is on final energy savings and for each Member State, and the $20 \%$ target is on primary energy savings (hence, includes savings in power and district heat generation and transmission, and oil refineries) and for the EU as a whole. Final energy savings directly translate into primary energy savings. And the $20 \%$ target is so high that all Member States will at least have to come close to $9 \%$ additional energy savings for the Union to meet the $20 \%$ target (for more explanations see Boonekamp 2010).

Furthermore, the ESD states that 'early action' can be counted towards the national energy savings target, albeit subject to guidelines by the European Commission. However, the ESD text can be interpreted in two ways: 'early action' could mean energy savings from technical or organisational action taken by market actors between 2008 and 2016 but facilitated by measures created before 2008 by Member States to achieve energy efficiency improvements (e.g., a building code revised in 2005 with tightened requirements) (we shall call this interpretation 'early measures'), or it could mean energy savings achieved between 1995 and 2008 due to energy efficiency improvement measures (we shall call this 'early energy savings'). A number of Member States have claimed early energy savings in their first national energy efficiency action plans (NEEAPs) filed in 2007. Up to $45 \%$ of the $9 \%$ target would be achieved through early energy savings by these Member States.

An analysis of these two issues has led to the following conclusions:

- If all energy savings, including those due to autonomous changes were allowed to count towards the ESD target, in the extreme case that (1) all autonomous change is due to energy end-use efficiency and (2) the Commission's estimate of $0.85 \%$ per year of autonomous improvement (EC 2006) is correct for energy enduse efficiency improvements in the end-use sectors covered by the ESD as well, only ca. $0.15 \%$ additional annual energy savings each year (or $1.35 \%$ in 9 years) would be needed to achieve the target (as $9 \%$ in 9 years means on average $1 \%$ per year, and $1.0 \%$ minus $0.85 \%$ is $0.15 \%$ ).

- If 'early energy savings' from action taken between 1995 and 2007 were allowed, if their average saving lifetime according to CWA (2007) was 15 years, and if they reached $0.6 \%$ per year in each year from 2002 to 2007 , only ca. $0.6 \%$ new annual energy savings would be required in each year from 2008 to 2016 (or $5.4 \%$ in these 9 years together).

- If both energy savings due to autonomous changes and 'early energy savings' from action taken between 1995 and 2007 were allowed, no additional energy savings at all might be needed between 2008 and 2016. The energy savings due to autonomous changes (estimated at $0.85 \%$ per year) could be higher than those that

\footnotetext{
${ }^{1}$ ESD implementation covers 9 years (2008-2016). The national targets were calculated in 2007, and consist for each Member State of $9 \%$ (or above) of its annual average energy consumption (in absolute terms (GWh)), based on a reference period (the most recent five-year period previous to 2008, for which data were available). The energy consumption taken into account in the ESD does not include that covered by the European Emission Trading Scheme (see Directive 2003/87/EC).

2 ,"brought about by natural replacement, energy price changes, etc." as stated in the EU Action Plan (EC 2006)
} 
remain to be made, after 'early energy savings' from action taken between 2002 and 2007 are counted towards the target of $9 \%$ (which could be as low as $0.6 \%$ per year as pointed out above). This would render the ESD meaningless for its stated goal to advance energy efficiency improvement measures and for its contribution to the overall $20 \%$ primary energy savings target.

What does this mean for a harmonised model of methods to evaluate energy savings for the ESD? If the ESD is to make a significant contribution to achieving the EU's target of $20 \%$ additional energy savings by 2020, as the 2006 EU Action Plan for Energy Efficiency assumed, the following political conclusions will need to be drawn for the implementation of the ESD:

1. Not all energy savings from all end-use actions to improve energy efficiency should be allowed to count for the ESD energy savings target but only energy savings additional to autonomous changes of energy efficiency. Member States should, under this condition, try with the highest appropriate effort to exclude energy savings due to autonomous changes from the calculation of ESD energy savings. A later section will present how to make bottom-up and top-down calculations of additional energy savings consistent with each other.

2. The best solution regarding 'early action' would be not to allow 'early energy savings' to count towards the ESD target. This will not put forerunners at a disadvantage, since they already have good experiences and have many - early - measures in place, which will create new energy savings during the 2008 to 2016 period.

However, it was not up to the EMEEES project to decide on the interpretation of the ESD. We therefore decided that our methods and case applications should enable Member States to both calculate all energy savings and the additional energy savings that are an impact of energy efficiency improvement measures. Furthermore, the methods and case applications need to enable Member States to assess whether early energy savings achieved before 2008 still exist in 2016.

Following these considerations, the EMEEES project has developed methods and case applications that would allow the calculation of both additional or all energy savings. More precisely:

- $\quad$ Additional energy savings ${ }^{3}$ are understood as those that are additional to autonomous energy savings (i.e., to savings that would occur without energy efficiency programmes, energy services, and other energy efficiency policies such as building codes or energy efficiency mechanisms). These additional energy savings include additional energy savings due to existing policies, programmes, and services that are ongoing or have a lasting effect ('early measures').

- $\quad$ By contrast, all energy savings are those resulting from all technical, organisational, or behavioural actions taken at the end-use level to improve energy efficiency, whatever their driving factor (or cause) (energy services, policies, or market forces and autonomous technical progress).

The ESD monitoring system can include bottom-up or top-down methods for monitoring and evaluation, or combinations of both. The next section of this paper presents the principles of bottom-up and top-down methods used by the EMEEES project.

\section{Overview of Bottom-up and Top-down Methodology}

\section{Bottom-up methods}

The harmonised rules for bottom-up evaluation methods proposed by EMEEES are organised around four steps in the calculation process (see Figure 1). These steps and their sub-steps are summarized in (Broc et al. 2010) and presented in detail in a separate report (Broc et al. 2009). They have been used in each case application. The bottom-up methods themselves are presented in this section just for comprehensiveness to the reader, although they have been common for more than 20 years (cf. sources such as CPUC 2006, EVO 2010, SRCI et al. 2001, TecMarket Works et al. 2004, Vreuls et al. 2005). What was the special task of EMEEES and is, therefore, its new contribution, is (1) how energy savings for the whole country from different measures targeting one end use or technology can be measured (cf. the bottom-up methodology report, Broc et al. 2009 and the bottom-up summary report, Vreuls et al. 2009, and the 20 case applications); (2) how these calculated energy savings can be made comparable between countries - the issue of harmonisation, addressed by a three-level approach briefly presented in the next part of this paper and in each of the 20 case applications; (3) how to make energy savings calculated by bottom-up and top-down methods comparable (cf. Table 2 in this paper). Finally, a new feature of the ESD is the target year and, hence, the special attention needed for the 'lifetimes' of energy savings. This is step 4 in our bottom-up calculations, cf. Figure 1.

Bottom-up methods start from calculating annual energy savings for one final consumer or one piece of equipment. These socalled unitary gross annual energy savings can normally not be directly measured but need to be calculated from the difference between the energy-efficient situation after an energy efficiency improvement measure and a hypothetical baseline. For example, the savings for a specific dwelling are the calculated or measured gas use after a thermal insulation measure compared to the calculated or measured gas use before, normalising measured values for fluctuation in heating degree days. In some cases, the choice of the baseline is decisive for whether all or additional savings will be calculated (cf. discussion above).

\footnotetext{
${ }^{3}$ For general discussions about additionality and baseline, see also (Vine 2008).
} 
Then these so-called unitary energy savings per consumer or equipment are added together for all consumers or equipment affected by an energy efficiency improvement measure. However, the resulting total gross annual energy savings need to be corrected by some factors. The ESD requires avoidance of double counting but accounting for multiplier effects ${ }^{4}$. Avoiding double-counting is an important issue when trying to evaluate overall energy savings for one country or region from multiple energy efficiency policies and measures with bottom-up methods. The ESD, in contrast, does not mention correction for freerider effects, i.e., savings by consumers who would have taken the action without energy efficiency programmes, energy services, and other energy efficiency policies. Correcting for free-rider effects or not is, therefore, another element in the calculation of all or additional energy savings (cf. Table 2 below for details on bottom-up calculations, baselines, and correction factors).

All these correction factors will add potential uncertainty to the results and need careful evaluation.

\begin{tabular}{|c|c|}
\hline $\begin{array}{l}\text { + summing up across participants } \\
\text { or units } \\
+ \text { double counting, multiplier effect, } \\
+ \text { other gross-to-net correction } \\
\text { factors (e.g., free-rider effect } A))\end{array}$ & $\begin{array}{l}\text { Step 1: unitary gross annual energy savings (in } \mathrm{kWh} / \mathrm{year} \text { per } \\
\text { participant or unit, average or individual) } \\
\text { Example: how much energy is saved annually by using an A++ fridge } \\
\text { instead of an A or A+ fridge? } \\
\text { Step 2: total gross annual energy savings (taking into account } \\
\text { the number of participants or units, in kWh/year) } \\
\text { Example: how many A++ fridges were sold (within the EEI } \\
\text { programme)? } \\
\text { Step 3: total ESD annual energy savings in the first year of } \\
\text { the EEI measures (taking into account double counting, multiplier } \\
\text { effect, and other gross-to-net correction factors, in kWh/year) } \\
\text { Example: how many A++ fridges are promoted by more than one EEI } \\
\text { programme and might be double-counted? } \\
\text { Step 4: total ESD energy savings achieved in the year } 2016 \\
\text { (in kWh/year, taking account of the timing of the end-use (EEI) } \\
\text { action, and its lifetime) } \\
\text { Example: how many A++ fridges due to the programme are still in } \\
\text { use in 2016? }\end{array}$ \\
\hline
\end{tabular}

A) the free-rider effect will only be relevant, if the aim of the evaluation is to calculate energy savings additional to autonomous changes, cf. discussion above. The free-rider effect is not mentioned in the ESD.

Note: $\mathrm{EEI}=$ energy efficiency improvement

Figure1. A four steps bottom-up calculation process (source: EMEEES)

Two general formulas can be derived from this four-step process for the total ESD annual energy savings in the first year; they are classic bottom-up evaluation formulas (cf., e.g., also SRCI et al. 2001, p. 65):

1. If average unitary gross annual energy savings for a unit of end-use action can be defined, the formula will be:

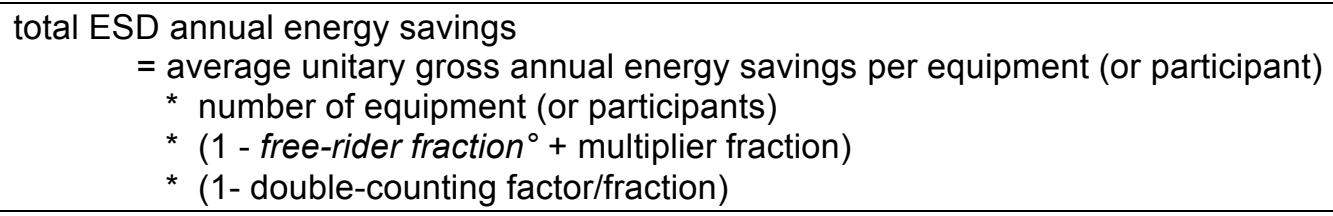

○ only if additional energy savings are calculated

2. If individual unitary gross annual energy savings for one (usually larger) final consumer benefitting from an energy efficiency improvement measure (called a participant) have to be used, the formula will be:

$4 \quad$ The multiplier (or spill-over) effect enhances the initial effect of energy efficiency improvement measures. According to Annex IV-5 of the ESD, the multiplier effect means that "the market will implement a measure automatically without any further involvement from the authorities or agencies referred to in Article 4-4 or any private-sector energy services provider". 
total ESD annual energy savings

= sum of individual unitary gross annual energy savings per participant

* (1 - double-counting factor/fraction (average or individual) )

* (1 - free-rider fraction ${ }^{\circ}+$ multiplier fraction)

${ }^{\circ}$ only if additional energy savings are calculated

Equation $1 b$

In both cases of the formula:

- $\quad$ the free-rider fraction is the share of free-riders, between 0 and 1

- the multiplier fraction is equivalent to spill-over effect and is $\geq 0$

- the double counting factor/fraction is a coefficient or fraction between 0 and 1

Table 4 in Appendix 1 reminds the main calculation methods, as summarised from existing literature (mainly EVO 2010, SRCI et al. 2001, TecMarket Works et al. 2004, Vreuls et al. 2005).

The case applications proposed were not meant to be sophisticated 'state-of-the-art' methods. They were developed taking into account the differences in experience and means availability among the Member States. The objective was to launch a learning process, where each country can start from its current experience level, also considering possible data limitations and future changes related to other European regulations (e.g., the Directive on Energy Performance of Buildings).

That is why the most important part of the bottom-up methodology proposed was a systematic way to describe the methods that can finally be used by the Member States. Reporting the same minimum set of information is the first step towards a harmonised evaluation system (see below). Of course, in a first period, countries will start with different practices, which may be inconsistent sometimes, making it difficult to compare results. But using reporting requirements together with experience sharing should lead to more harmonisation over time.

Last but not least, harmonisation does not mean standardisation at all. Anyhow, each country will always have a specific context, leading to particular policy objectives. Consequently, their evaluation objectives may be different. So it would be counterproductive to impose the same evaluation methods to all countries. This would lead to encouraging the same standardised actions everywhere, which is definitely not the most efficient way to achieve the energy savings potentials. The same pragmatic principles were used when defining the top-down methods, as explained in the next section.

\section{Top-down methods}

Top-down methods rely on energy efficiency indicators calculated from national statistics (also called ,top-down indicators', e.g., ODYSSEE indicators). There are several types of indicators:

- $\quad$ Specific energy consumption indicators for a well-defined type of new appliance, equipment, or vehicle, measuring the average energy consumption of the sold equipment or the equipment stock in energy/appliance/year or energy/km

- Unit energy consumption indicators of a sub-sector or sector, e.g., electricity/employee/year in the tertiary sector, process fuels per ton of cement, heating energy $/ \mathrm{m}^{2}$ of dwelling/year

- Indicators on the diffusion of energy-saving technologies, such as $\mathrm{m}^{2}$ of solar thermal collectors, or energy-efficient transport modes, such as the share of trains and ships in goods transport.

Furthermore, a special econometric method based on the analysis of price elasticities can be used to evaluate the effects of energy taxation from any indicator.

The analysis of top-down methods done by EMEEES is presented in a summary report (Lapillonne, Bosseboeuf\&Thomas 2009) with a separate Annex presenting the ODYSSEE indicators in more detail, and a second summary report on the topdown cases analysed in EMEEES (Lapillonne\&Desbrosses 2009).

With top-down methods, the overall energy savings are calculated from the difference in the current value of a particular statistical indicator used in a certain year, and the hypothetical value that is calculated for that year from a reference trend assumed. The simplest form of a reference trend is to take the value of the indicator in a base year as the reference. For example, if the average amount of gas use per dwelling decreases with respect to a base year, the difference is taken as energy savings. The resulting energy savings have been called 'total' savings (however, 'apparent total' savings would be a better name), and the assumption is easily made that these are equivalent to all energy savings.

However, this intuitive assumption is only meaningful for indicators that have the 'right' trend over the years, a trend towards higher energy efficiency. But that is only the case for about $60 \%$ of all the 14 ODYSSEE indicators and the countries analysed in EMEEES. For some indicators, there are all cases of countries with a decreasing, increasing, or stable trend. This is because there are structural effects that also lead to changes in the indicator value but have nothing to do with energy efficiency. They can be due, e.g., to increased size of refrigerators, new IT equipment increasing electricity use in the service sector, or changes in the product mix of an industry sub-sector. Therefore, these structural effects need to be corrected before calculating energy savings, if this is possible with a reasonable effort. Such correction could be done by bottom-up modelling of some of the effects to correct them. With all structural effects removed, 'apparent total' energy savings should be equal to all energy savings. It may, however, be difficult to judge from the results whether all structural effects have been removed, and it may be costly to do the correction.

An equivalent way, in principle, could therefore be to calculate the reference trend for all energy savings from bottom-up modelling of the energy consumption underlying the indicator, with zero energy efficiency changes in the model. However, the feasibility of this approach was not tested in EMEEES. 
For calculating additional energy savings using top-down methods, the approach taken in EMEEES is a regression analysis of past trends of an indicator that would reflect the autonomous changes. This past 'autonomous trend' found in this regression analysis will then be extended into the future to serve as the reference trend for calculating energy savings from the difference between the actual value of the indicator in the target year and this reference trend. Figure 2 below presents an example of application for this approach. This approach was conclusive in some cases but not in others. This result for the indicators analysed does not mean the approach is not useful or feasible. Rather, it means that statistical data available for EU Member States on underlying structural changes and sectoral drivers of energy consumption do not allow a full multivariate analysis (cf. Horowitz 2011 as an example) that may lead to more plausible results. In those inconclusive cases, again, bottom-up modelling of the energy consumption underlying the indicator and the structural changes may provide a way forward, but EMEEES was not able to test it (cf. Table 2 below for details on top-down calculations and correction factors). Using such regression analysis in principle allows to evaluate energy savings compared to an autonomous trend, even if the trend of the underlying indicator is flat or even increasing over time and, hence, does not allow to calculate 'apparent total' energy savings. However, there is significant potential uncertainty in the autonomous trend.

Simple econometric methods were used, on purpose, to quantify the impact of energy market prices and trends, taking into account several criteria:

- $\quad$ the need for transparency and of harmonisation among countries,

- the easiness of implementation and of their understanding, as such methods would ultimately need to be applied by the countries;

- $\quad$ finally, the data limitations, in particular for additional explanatory variables (e.g., price/tax on cars, cost of equipment) and the uncertainty of the data handled.

The typical regression equation to derive the reference trend for additional energy savings considered was follows:

$$
\ln E S=a+b T+c \ln P+d \ln A+K
$$

with : In : logarithm; ES: energy saving indicator; a: a constant; b: trend; T: time; P : energy price; c : price elasticity $^{5}$; A: macro economic variable (e.g. GDP) to capture the impact of business cycles; $d$ : elasticity to GDP; K: constant coefficient

Equation 2

The estimate of the regression coefficient is made over a period ending before the period on which the effects of energy efficiency improvement measures will have to be assessed (e.g., before 1995). Then using the coefficient, the impact of the different effects can be modelled, using driver data, to obtain the reference trend over the period on which the ESD savings will be calculated (i.e. 2008-2016) (Figure 2). Note that in this case, the downward trend of the modal share of rail and waterways in freight transport will lead to increasing energy consumption, hence no 'apparent total energy savings' can be calculated, but energy savings vs. the trend can. The figure presents a policy effect that reverses the trend and leads to an increasing modal share of the energy-efficient transport modes (upper curve). The price effect can be separated into two components, ex-tax energy price (market component) and an energy tax if that exists (policy component), using the same price elasticity .

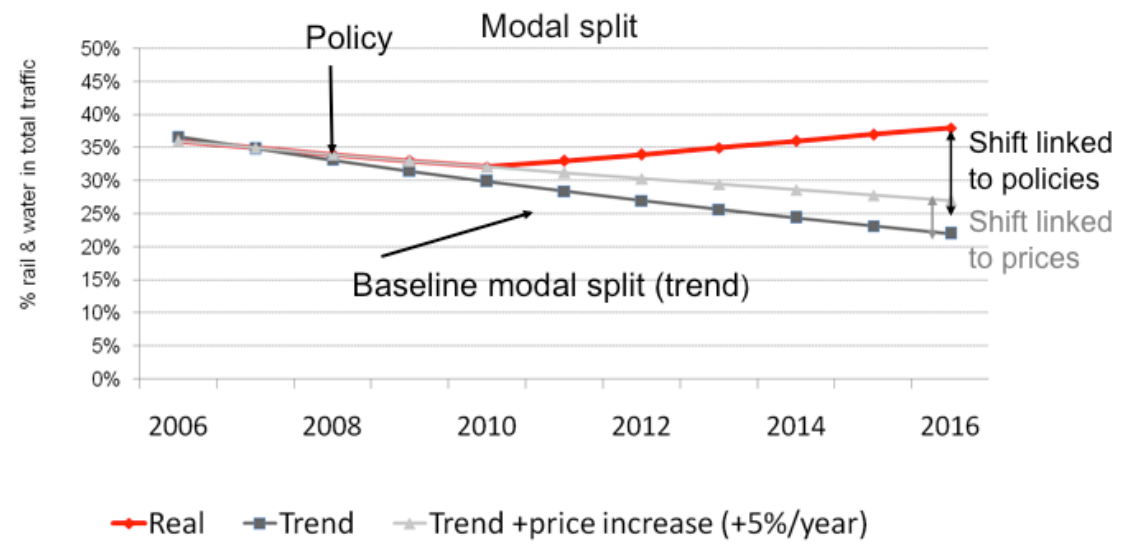

Figure 2. An example of the calculation of changes in an indicator vs. the reference trend determined through regression analysis (indicator on modal shares in goods transport; the example models the assumption of the implementation of a policy in 2008 with first impact in 2010: rail and water traffic market share assumed to increase by $1 \%$ each year) (source: EMEEES)

$5 \quad$ Price elasticity may be differentiated between upward and downward price elasticity. 


\section{Addressing Harmonisation Issues}

A harmonised model of bottom-up and top-down calculation methods should be developed and used for the ESD reporting (cf. ESD article 15). Harmonisation should give a reasonable freedom for the Member States (following the principle of subsidiarity), while the results reported can be compared. Therefore, the methods and the 20 bottom-up and 14 top-down case applications developed by the EMEEES project are a starting point, but these methods and applications are not intended to exclude the use of own methods and further methods for other sectors, end uses, and kinds of energy services and energy efficiency improvement measures by the Member States. However, harmonisation should be ensured by key elements proposed by EMEEES: a general structure both for the documentation of bottom-up and top-down energy savings and for the calculation itself, with the selection of baseline and baseline parameters as well as correction factors, and a dynamic approach to ensure improvement over time.

In bottom-up measurement, a three-level approach has been proposed by EMEEES to facilitate such improvement over time: Level 1 is based on EU default values for energy savings per unit or for other parameters, to allow countries that don't have monitoring and evaluation experiences a quick start. EMEEES has proposed a number of such default values in bottom-up case applications, available at www.evaluate-energy-savings.eu. The default values are conservative and yield relatively low energy-savings results, in order to encourage own monitoring, survey, and measurement activities at least at level 2, the national level. Evaluation of samples can be used to calculate national average default values that can be used to calculate overall energy savings. At level 3, measure-specific values can be developed to prove that savings are higher than national averages; measure-specific values can also mean that individual energy savings can be calculated for larger final consumers benefiting from an energy efficiency improvement measure (then using equation $1 \mathrm{~b}$ ).

These EMEEES proposals were based on past experiences and existing literature (e.g. CPUC 2006, EVO 2010, SRCI et al. 2001, TecMarket Works et al. 2004, Vreuls et al. 2005), taking account of the ESD specificities. Bottom-up and top-down methods can both be used for calculating ESD energy savings. In order to avoid 'adding up apples and oranges', the key elements for top-down and bottom-up should also be mutually consistent. EMEEES findings on how to achieve such consistency will be presented in the next section of this paper. The development of such a harmonised model is a learning process, and the methods should be improved in the future since more experiences from Member States will become available and lessons can be learned.

In the ESD process, the EMEEES results are not to be directly and compulsorily used by the Member States. They are inputs to the work of the European Commission and the ESD Committee. According to the harmonisation level needed for the ESD implementation, the decisions from the Commission and the ESD Committee may correspond to different levels of requirements ("could, should or shall"). It is therefore necessary to clarify what level of requirements the different EMEEES proposals correspond to. We hereafter distinguish supporting resources, reporting checklist and general principles, as described in Table 1 below.

Table 1. Three main categories of methodological outcomes

\begin{tabular}{|c|c|c|}
\hline Supporting Resources & Reporting Checklist & General Principles \\
\hline $\begin{array}{l}\text { Concrete evaluation methods Member } \\
\text { States COULD use when they are } \\
\text { looking for technical support. } \\
\text { (example of provided information: } \\
\text { examples of algorithms, formulae, or } \\
\text { data commonly used to calculate a } \\
\text { baseline for heating systems) }\end{array}$ & $\begin{array}{l}\text { List of questions Member States } \\
\text { SHOULD answer in their future NEEAP } \\
\text { to provide a consistent set of information } \\
\text { about how they assessed their energy } \\
\text { savings results. } \\
\text { (e.g.: reporting what data were used to } \\
\text { calculate the baseline values) }\end{array}$ & $\begin{array}{l}\text { Harmonised rules Member States } \\
\text { SHALL apply when evaluating } \\
\text { their energy savings results. } \\
\text { (e.g.: update frequency for } \\
\text { baselines) }\end{array}$ \\
\hline $\begin{array}{l}\text { To be available for all Member States } \\
\text { (no need for decision) }\end{array}$ & $\begin{array}{l}\text { To be discussed by the ESD Committee } \\
\text { (but no need for decision) }\end{array}$ & $\begin{array}{l}\text { To be decided by the European } \\
\text { Commission and the ESD } \\
\text { Committee }\end{array}$ \\
\hline From specific issues... & & $\rightarrow$...To general issues \\
\hline
\end{tabular}

The supporting resources are made available by the Commission to Member States. These materials are mainly developed by Intelligent Energy-Europe projects, such as EMEEES, for concrete evaluation methods and pilot tests. Data on average annual energy consumption (for equipment stocks or markets) can also be found in preparatory studies for implementing the EuP (Energy-Related Products) Directive (2009/125/EC).

As these resources are not mandatory, they do not require a decision (validation) from the ESD Committee.

The reporting checklist is to address issues that do not necessarily need to be harmonised at an EU level, but that are relevant when evaluating energy savings. This checklist is a quality assurance (on data, sources, etc.) that would enable the Commission to well compare data provided by the Member States on their achieved energy savings. An example of such a checklist can be found in (Vine \& Sathaye, 1999). The checklist specific to the ESD proposed by the EMEEES project will have to be validated by the European Commission and is included in the final report of EMEEES (Wuppertal Institute 2009: Appendices 2 and 3 of that report).

The checklist does not require Member States to apply a given method nor to include all possible issues in their evaluations. But they are asked to report whether they address the listed issues, and how. By pinpointing the main evaluation issues, the 
aim is to induce better evaluation designs. And by structuring the evaluation reporting, the checklist will also facilitate the collection and analysis of experience to share between Member States.

General principles correspond to the major and priority issues, for which harmonisation is required in order to achieve a harmonised evaluation system for all Member States. Their application will be mandatory, so they require a consensual decision from the ESD Committee and the Commission.

These general principles would be proposed, e.g., by the ESD Working Groups (or ESD Sub-Committee) ${ }^{6}$. The EMEEES work provided analysis about possible options that might be considered in these decisions.

Debates in the ESD Committee and Sub-Committees' meetings highlighted how difficult it is to get a consensus among the 27 Member States on harmonised evaluation rules. Indeed, sometimes lively discussions are needed so that national representatives let own experiences, standpoints or habits aside in order to agree on common proposals. Member States will always better accept them when they are in line with the rules they are used to. The EMEEES proposal to distinguish several levels of requirements is then very useful, as it focuses the debates on the highest level (i.e. general principles) and therefore limits the discussions on the main issues. At the same time, national representatives are reassured to see that for lower requirement levels they retain freedom on how to manage ESD implementation in their country.

\section{Main Elements of Calculation Needed to Ensure Consistent Results Between Bottom-up and Top-down Methods}

As said above, the ESD monitoring system can include bottom-up or top-down methods for monitoring and evaluation, or combinations of both. A major task for developing a harmonised calculation system is, therefore, that the results of either bottom-up or top-down calculation for the same end use or type of measure must be consistent and comparable with each other. This requires that the elements of calculation need to be chosen in a consistent manner for both bottom-up and topdown calculations, and for the two evaluation targets introduced above: additional and all energy savings.

This section presents the elements that would ensure consistency in principle, see Table 2. It must be noted that only the elements of bottom-up and top-down calculations in either of the two rows of the table, i.e., additional energy savings and all energy savings, respectively, are consistent with each other. Using the elements of bottom-up calculation from one and those of top-down from the other row of the table would be highly inconsistent because it would lead e.g. to estimates of all energy savings by bottom-up methods and additional energy savings by top-down methods or vice-versa.

Notwithstanding these principles, the actual EMEEES methods and case applications have looked for a pragmatic solution and often propose to drop some effects from the calculation, if there is no way, or it is too expensive to evaluate them.

Table 1. Elements of calculation for the evaluation of additional or all energy savings that will ensure consistency between bottom-up and top-down methods

\begin{tabular}{|c|c|c|}
\hline $\begin{array}{l}\text { Evaluation } \\
\text { target }\end{array}$ & Elements of bottom-up calculation & Elements of top-down calculation \\
\hline $\begin{array}{l}\text { Additional } \\
\text { energy } \\
\text { savings }\end{array}$ & $\begin{array}{l}\text { Case 1: replacement of existing equipment } \\
\text { Baseline = Without measure situation (market } \\
\text { baseline; e.g., for refrigerators, the average } \\
\text { annual energy consumption of the not } \\
\text { energy-efficient models sold) } \\
\text { Case 2: add-on energy efficiency investment } \\
\text { without replacement of existing equipment or } \\
\text { building (e.g., thermal insulation) } \\
\text { Baseline = Before action situation (in the } \\
\text { example, energy consumption of the building } \\
\text { before thermal insulation) } \\
\text { Case } 3 \text { : new building or appliance: the before } \\
\text { situation does not exist and a reference has } \\
\text { to be created. } \\
\text { Baseline = A reference situation }{ }^{2} \text { (e.g., (2) the } \\
\text { existing market) } \\
\text { Apart from avoiding double-counting and } \\
\text { taking multiplier effects }{ }^{1} \text { into account, also } \\
\text { free-rider effects }{ }^{1} \text { should be analysed in } \\
\text { principle }\end{array}$ & $\begin{array}{l}\text { Case a): for specific energy consumption indicators } \\
\text { related to an end-use equipment (e.g., cars, } \\
\text { refrigerators): } \\
\text { Reference trend = EU default value (based on a } \\
\text { regression analysis for all countries with data available, } \\
\text { and on the average of the three countries with the } \\
\text { slowest trend found in the analysis) } \\
\text { Case b): for other types of indicators (unit energy } \\
\text { consumption of sectors, diffusion indicators): } \\
\text { b1) if possible, } \\
\text { Reference trend for one country = extrapolation of } \\
\text { historical trend before measures (from regression } \\
\text { analysis for each country) } \\
\text { b2) otherwise, the only option that appears consistent, } \\
\text { however, feasibility was NOT tested within EMEEES: } \\
\text { Reference trend = result of direct (bottom-up) modelling } \\
\text { calculation or of correction of the indicator for structural } \\
\text { effects, using (bottom-up) modelling } \\
\text { In all cases: } \\
\text { correction of reference trend for energy market price } \\
\text { increase, using a default value for the short-term price } \\
\text { elasticity of } 0.1 \text { or } 0.2\end{array}$ \\
\hline
\end{tabular}

\footnotetext{
${ }^{6}$ To facilitate the decisions of the ESD Committee, two sub-committees were created to examine the most important issues related to bottom-up and top-down evaluation approaches, respectively.
} 


\begin{tabular}{|c|c|c|}
\hline $\begin{array}{l}\text { All } \\
\text { energy } \\
\text { savings }\end{array}$ & $\begin{array}{l}\text { Case 1: replacement of existing equipment } \\
\text { Baseline = Before action situation (stock } \\
\text { baseline if aggregated units are used, e.g., } \\
\text { stock of refrigerators) } \\
\text { Case 2: add-on energy efficiency investment } \\
\text { without replacement of existing equipment or } \\
\text { building } \\
\text { Baseline = Before action situation } \\
\text { Case 3: new building or appliance: the before } \\
\text { situation does not exist and a reference has } \\
\text { to be created. } \\
\text { Baseline = A reference situation }{ }^{2} \text { (e.g., (1) the } \\
\text { existing stock) } \\
\text { Apart from avoiding double-counting, only } \\
\text { multiplier effects have to be analysed in } \\
\text { principle } \\
\text { In order to calculate all savings, those from } \\
\text { end-use actions not affected by policies or } \\
\text { services have to be collected, too. }\end{array}$ & $\begin{array}{l}\text { The option that appears most consistent; however, } \\
\text { feasibility was NOT tested within EMEEES: } \\
\text { Reference trend = result of (bottom-up) modelling } \\
\text { calculation of the development of the indicator without } \\
\text { any technical, organisational, or behavioural end-use } \\
\text { actions taken to improve energy efficiency. } \\
\text { In particular, zero change of the indicator between } \\
\text { years would only be a correct reference trend, if all } \\
\text { structural effects influencing the indicator value were } \\
\text { removed }{ }^{3} \text {. This may be feasible for specific energy } \\
\text { consumption indicators related to an end-use } \\
\text { equipment (e.g., cars, refrigerators) and for the stock of } \\
\text { solar water heaters. In these cases: } \\
\text { Reference trend = base year (2007) value of the } \\
\text { indicator }\end{array}$ \\
\hline
\end{tabular}

1 In practice, this is often difficult, and so it is recommended to only assess multiplier and free-rider effects for EEI measures exceeding a threshold of annual energy savings of, e.g., 40 million kWh of electricity or 100 million kWh of other fuels. According to experience, the additional costs for evaluating these effects would still be below $1 \%$ of the overall costs of measures above this threshold.

2 Reference situation could be: (1) the existing stock, (2) the existing market; (3) the legal minimum performance; (4) the Best Available Technology (BAT) (only for technology procurement and similar measures that aim to bring technologies better than BAT to the market)

3 Despite the efforts of ODYSSEE to remove structural effects, the 'total apparent' energy savings calculated by taking zero change of the indicator between years as the reference trend are, for most ODYSSEE indicators, not consistent with calculating all energy savings, and anyway feasible only for about $60 \%$ of all ODYSSEE indicators/countries analysed in EMEEES case studies (for the others, there appear to be negative 'total apparent' savings). Taking these 'total apparent' energy savings for proving the ESD energy savings would be like a lottery for the Member States.

\section{Applicability of the Methods Developed by EMEEES to Prove Attainment of the Member States' ESD Targets}

In the EMEEES project, 20 bottom-up (BU) and 14 top-down (TD) case applications have been developed to calculate energy efficiency improvement in various end-use sectors. The choice of case applications was based on targeted energy use, where relatively large energy savings were expected. But available experience with evaluation methods has played a role as well in the choice.

EU countries can choose from these case applications when fulfilling the demands of the ESD:

- $\quad$ proving that the $9 \%$ or higher savings target has been met for 2016 (or the intermediate target for 2011)

- $\quad$ showing that BU case applications cover at least $20-30 \%$ of the energy use covered by the ESD

- $\quad$ taking account of overlap in the scope of TD and BU case applications focusing on the same targeted energy use, in order to avoid double counting of energy savings.

Figure 3 shows how, in an interactive process, countries can choose a set of case applications that meets the ESD demands. In step c the check on coverage takes place, in step d the correction for overlap ("net" instead of gross savings) and in step e the check on the $9 \%$ target. 


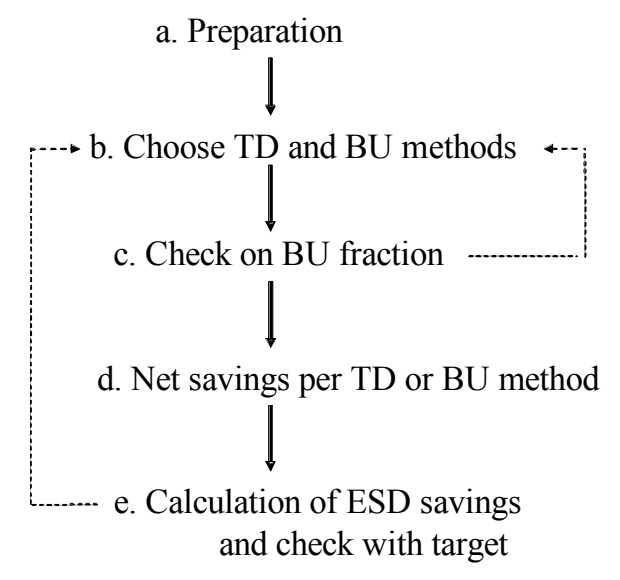

Figure 3. Process of evaluating ESD energy savings (source: EMEEES)

The question arose whether the chosen set of TD and BU case applications fits to the needs and circumstances of the different EU countries. Therefore, a check was made how the countries could prove the $9 \%$ energy savings and meet the $20-30 \%$ BU coverage. To this end, for all countries an analysis was made of the applied energy efficiency improvement measures in their national energy efficiency action plan (NEEAP), and which TD and BU case applications could be used to calculate the savings of these measures. The following conclusions emerge from the analysis:

- In case all BU case applications can be applied, they can achieve more than $90 \%$ coverage of the energy use

- All countries except 3 can prove minimum coverage of $20-30 \%$ for BU methods

- $\quad$ Large contributions are from: space heating in dwellings and passenger transport

- Horizontal measures are important for coverage, as their scope is large

- $\quad$ One-third of Member States could have problems proving the 9\% savings target with the EMEEES set of case applications, due to very different reasons, e.g., no transport measures in the NEEAP, no space heating (Malta), few measures in general.

Finally, it showed up that some case applications are lacking, e.g. on CHP, street lighting, and mobility management. Generally, the set of case applications is sufficient but countries may have problems if they have few BU methods for targeted energy use and no horizontal measures, since only 6 to 8 out of 14 TD case applications can usually be applied.

\section{Example Results from the Field Tests}

In co-operation with Member State governments, energy companies, and other organizations offering energy efficiency improvement measures, the EMEEES methods were tested in six pilot tests. These each evaluated ex post the energy savings from energy efficiency improvement measures implemented in various countries for a selected sector and energy end use by making use of the methods and case applications tested and also tested the compatibility of EMEEES methods with evaluation methods developed in these countries.

The Table 3 below reports the list of case applications that were tested, which are all bottom-up.

Table 3. List of case applications tested in EMEEES

\begin{tabular}{|l|l|c|c|c|c|}
\hline EMEEES case application & Sector & Italy & France & Denmark & Sweden \\
\hline Building envelope improvement & Residential & & $\mathrm{X}$ & \\
\hline Energy-efficient white goods & Residential & $\mathrm{X}$ & & & \\
\hline Condensing Boilers & Residential & $\mathrm{X}$ & $\mathrm{X}$ & & \\
\hline Improvement of lighting system & Tertiary (industry) & & & \\
\hline High efficiency electric motors & Industry & $\mathrm{X}$ & & & \\
\hline Variable speed drives & Industry & $\mathrm{X}$ & & & \\
\hline Energy audits & Tertiary and industry & & & $\mathrm{X}$ & \\
\hline Energy performance contracting & Tertiary and industry & & & & $\mathrm{X}$ \\
\hline
\end{tabular}


Out of the results, we would like to present some from the field tests performed in Italy ${ }^{7}$.

The pilot tests were performed under the Italian White Certificate scheme and focused on energy end-use actions addressing condensing boilers and white goods for the residential sector and electric motors and variable speed drives (VSDs) for the industrial sector. The tests concentrated on comparing the methods to calculate unitary gross annual energy savings between EMEEES and the Italian scheme. In general, pilot test outcomes indicated how it can be difficult to find the right balance between simplicity, accuracy and number of end uses covered when developing evaluation methods and case applications that could in principle be used in every EU Member State. For example, in the case of VSDs the field tests showed that the use of the proposed EMEEES EU default values could penalize countries like Italy where using national and more accurate methods developed for specific end uses (e.g. VSDs for water pumping systems) would result in less energy savings attributed. In the case of condensing boilers, the field tests indicated that the EMEEES default values were conservative in most parts of Italy except the very South. However, it was found that attempting to capture effects due to possible energy efficiency improvements of other parts of the heating system (like e.g. heat emitters, heating control or distribution systems) might be difficult in practice. The minimum evaluation requirement could be reduced to using EU default or national (level 2) or programme-specific (level 3) values for evaluating only energy savings due to condensing boiler installation. Furthermore, the results indicated that it would be good to restrict the use of the default values from this EMEEES case application to condensing boilers installations fulfilling simple operation standards that can guarantee real energy savings (e.g. to condensing boilers with modulated burners installed in heating systems where the return-water temperature does not exceed $60^{\circ} \mathrm{C}$ ). Concerning the EMEEES case application developed for energy-efficient motors, the field tests showed that it might be more appropriate and simpler if the EMEEES EU default values provided would just consist in EU default values of the energy savings attributable to the various possible motor application types and motor power ranges, rather than in EU default values for motor load factors, operating hours and motor efficiency that the evaluator should include in the calculation formula proposed to estimate the energy savings.

Most of the test outcomes were taken into account for the production of the final versions of the EMEEES case applications and the underlying methods.

\section{Conclusions and Outlook}

How much energy saving is $9 \%$ in 9 years? As we have seen, this largely depends on the interpretation that the European Commission and the Member States will take on some of the issues that are not really clearly defined in the ESD. The most important of these issues are the additionality or not of energy savings, and the eligibility of 'early energy savings'. We hope to have made the choices clearer with our analysis, and provided the ground on which the European Commission and the ESD Committee, and ultimately each Member State, can decide.

Whatever the decision on these two issues will be, the recommendation we conclude from our analysis for calculating overall energy savings on the national level, as required for the ESD, is as follows:

- Top-down calculation methods can be used for analysis of the energy savings from the electric appliances and vehicles sold each year, for which there is a well-defined statistical indicator of the average specific annual energy consumption per new unit of appliance or per new vehicle, and for solar water heaters. In these cases, the top-down indicator is well-suited to capture the effects of the whole package of measures, including multiplier (market transformation) effects. Bottom-up calculations are possible for appliances and vehicles, too, but it is often difficult to calculate multiplier (and free-rider) effects with them.

- Top-down methods are the way to calculate the effects of energy taxation and add them to the effects of bottom-up calculations for a sector, but only if these bottom-up calculations exclude free-rider effects. The energy savings due to taxation must not be added to results of top-down calculations on sectors or end-use equipment, if the latter already include an analysis to calculate the effects of energy taxation.

- It is the best and often the only possible way to use bottom-up calculation methods for all other end-use sectors, end-uses, and energy efficiency improvement measures. This is particularly the case for buildings, for the industry and tertiary sectors with their larger final consumers that are easier to monitor, and for modal shifts and eco-driving in transport. In some countries, top-down may be possible for modal shifts, too.

These recommendations are based on our analysis of case applications for bottom-up and top-down methods, as well as on practical experience in many countries and our pilot tests. They are based on the general trend of findings from these sources. However, the quality of data available in a country will finally determine which bottom-up or top-down methods are best to apply for evaluating the energy savings for the ESD from a sector, an energy end use, an end-use action, or a measure. It is, therefore, important that the accessibility, quality, and availability of data be considered already at the time when policies and measures are formulated and implemented in the ESD context. If evaluation methods and data collection are planned from the very beginning, this will improve data and evaluation results and often reduce the evaluation costs at the same time. Still,

\footnotetext{
${ }^{7}$ See the reports from the pilot tests available on the EMEEES website for information on the field tests performed in the other countries covered and (Broc et al. 2010) on the field tests in France.
} 
uncertainty will remain an issue in calculation of energy savings, since they can only be calculated in relation to a counterfactual (which we call 'baseline' in bottom-up and 'reference trend' in top-down calculations but which also includes some correction factors), and there will remain a trade-off between precision of results and evaluation effort.

The ESD has, therefore, required the European Commission to propose a harmonised calculation model of bottom-up and top-down calculation methods for ESD energy savings. Some thoughts were presented above about what harmonisation could mean in practice. As insiders report, the European Commission has based its proposals for the calculation model at least in part on the methods developed by the EMEEES project, however, the ESD Committee has not yet achieved an agreement. Debates seem to continue on the issues of simplicity vs. precision and which factors to include or not, the effort needed, and in which areas to use bottom-up vs. top-down calculations. This also appears to be based on traditions that some Member States have in using methods, or their level of policy ambition. Latest reports from insiders indicate that a set of non-binding methods recently proposed by the European Commission tend to simplify things too much: proposing the top-down calculation of 'apparent total savings' by using the base year value of an indicator as the reference trend (which we think is like playing lottery on the energy savings that are calculated, as discussed above below Table 2), and consistently calculating all energy savings with static 2007 baselines in the bottom-up calculations, which only cover buildings and appliances (but use to a good extent the formulas developed in EMEEES case applications). Maybe this is the minimal consensus that the EU Member States and the Commission can agree upon. But it is far from being accurate in calculating the real ESD energy savings. By contrast, using the pragmatic methods proposed by EMEEES would not need much higher evaluation effort but bring much higher accuracy in calculation. Fortunately, Member States can use their own methods as well, and there is also a CEN standard for calculation of energy savings under preparation, which makes more use of the results by EMEEES for bottom-up calculations.

Looking at harmonisation, certainly the Commission and the Member States could decide to use as many default values as possible. EMEEES has developed some proposals in this area, too. They will calculate rather low levels of energy savings to encourage Member States to perform national evaluation efforts.

On the other hand, the precision of results will deliberately be higher if national level 2 and 3 calculations (bottom-up) and national reference trends (top-down) are used, but with harmonised rules for a) definition of formulas, parameters, monitoring, and calculation procedures, particularly for the counterfactual, and b) harmonised reporting of results. This is certainly an area, in which more experience needs to be collected in the next round of NEEAPs in 2011. These NEEAPs will include the first ex-post calculations of energy savings. And we again very strongly recommend to require harmonised reporting using at least a format such as the reporting checklists we have developed and presented in Appendices 2 and 3 of the final report. This will then allow the Commission to better judge the plausibility and comparability of savings (and hence efforts) between Member States and in many cases also a verification of the reported energy savings, using models such as the adapted MURE assessment tool developed by EMEEES. The template that the European Commission has prepared for the 2011 NEEAPs is a step forward in this direction. It includes elements common with the EMEEES checklists but is not yet as detailed. A careful analysis of the plans and the effort that Member States needed to prepare them will provide insight on how the next NEEAPs in 2014 may be further refined, e.g., by more detail in Annexes.

Finally, the experience gained through this project highlights issues and possible solutions that may be useful in other contexts. It is likely that other frameworks similar to the ESD will create the need for countries, provinces or states to report to a central body, especially in big countries (e.g., in the US, China, India). The US experience showed that so far the evaluation rules and practices are very different from one state to another (Michals and Titus 2006). This situation is therefore not so different from the European one.

\section{Acknowledgements}

The authors wish to thank the European Commission for the financial support to the EMEEES project, and all partners of the EMEEES project for their contributions to the results presented here.

\section{References}

All reports and case applications produced by the project are available at www.evaluate-energy-savings.eu. With regard to the methods developed by EMEEES, they include:

- $\quad$ The EMEEES final report (Wuppertal Institute 2009)

- Two summary reports on methods: bottom-up (Vreuls, Thomas\&Broc 2009) and top-down (Lapillonne, Bosseboeuf\&Thomas 2009)

- $\quad$ Bottom-up methodological report (Broc et al. 2009)

- 20 bottom-up case applications papers

- $\quad$ Compilation report on 14 top-down case studies (Lapillonne\&Desbrosses 2009) 
- A report on consistency and the integration of the savings from bottom-up and top-down methods (Boonekamp\&Thomas 2009)

- $\quad$ The EMEEES checklists for reporting the results of bottom-up and top-down evaluations of energy efficiency improvement measures, Appendices $2 \& 3$ of (Wuppertal Institute 2009).

Boonekamp, P.G.M. (2010). How much will the Energy Service Directive contribute to EU energy and emissions goals? Energy efficiency, Online First, DOI 10.1007/s12053-010-9088-0, pp.1-17.

Boonekamp, P.G.M., and Thomas, S. (2009). Harmonised and integrated bottom-up and top-down methods to evaluate the ESD energy savings. Report from the EMEEES project. ECN, Petten and Wuppertal Institute, Wuppertal.

Broc J.S., Osso D., Baudry P., Adnot J., Bodineau L. and Bourges B. (2010). Consistency of the French white certificates evaluation system with the framework proposed for the European energy services. Energy efficiency, Online First, DOI: 10.1007/s12053-010-9100-8, pp. 1-22.

Broc, J.-S., Adnot, J., Bourges, B., Thomas, S., and Vreuls, H. ( 2009). The development process for harmonised bottom-up evaluation methods of energy savings. Ecole des Mines de Nantes, Nantes.

California Public Utilities Commission (CPUC) (2006). California Energy Efficiency Evaluation Protocols: Technical, Methodological, and Reporting Requirements for Evaluation Professionals. Report prepared by the TecMarket Works Team, CPUC, San Francisco, CA.

CWA (2007). CEN Workshop Agreement CWA 15693. April 2007. Saving lifetimes of Energy Efficiency Improvement Measures in bottom-up calculations. CEN, Brussels.

European Commission (EC) (2006). Action Plan for Energy Efficiency: Realising the Potential. Communication from the Commission COM(2006)545 final. European Commission, Brussels, 19 October 2006.

EVO (2010) International Performance Measurement \& Verification Protocol (IPVMP) - Volume I : Concepts and Options for Determining Energy and Water Savings. Washington D.C.: Efficiency Valuation Organization, Revised edition of September 2010 .

Horowitz, M.J. (2011). Measuring the savings from energy efficiency policies: a step beyond program evaluation. Energy Efficiency (2011) 4, 43-56

Lapillonne, B., Bosseboeuf, D., Thomas, S. (2009). Top-down evaluation methods of energy savings, Summary report. Enerdata, Grenoble. ADEME, Paris. Wuppertal Institute, Wuppertal.

Lapillonne, B., and Desbrosses, N. (2009). Top-down evaluation methods of energy savings. Case studies summary report. Enerdata, Grenoble.

Michals, J. and Titus, E., 2006. The Need for and Approaches to Developing Common Protocols to Measure, Track, and Report Energy Efficiency Savings in the Northeast. In: Proceeding of the ACEEE (American Council for an Energy-Efficient Economy) 2006 Summer Study, 13-18 August 2006, Pacific Grove, CA, pp. 8.179-8.190.

SRCI, NOVEM, Electricity Association, MOTIVA, Norsk Enok og Energi AS, Centre for Energy Conservation of Portugal, Elkraft system, SEVEn, Energy Saving Trust, Wuppertal Institute (2001). A European Ex-Post Evaluation Guidebook for DSM and EE Service Programmes. SAVE Project No. XVII/4.1031/P/99-028, April 2001

TecMarket Works, Megdal \& Associates, Architectural Energy Corporation, RLW Analytics, et al. (2004). The California Evaluation Framework. Report prepared for the Southern California Edison Company as mandated by the California Public Utilities Commission, K2033910, Revised September 2004. Available at: http://www.calmac.org/toolkitevaluator.asp. Accessed February 14, 2011.

Vine, E. (2008). Breaking down the silos: the integration of energy efficiency, renewable energy, demand response and climate change. Energy Efficiency, 1(1), pp.49-63.

Vine, E. and Sathaye, J. (1999). Guidelines for the Monitoring, Evaluation, Reporting, Verification and Certification of Energy-Efficiency projects for Climate Change Mitigation. Report prepared for the U.S. Environmental Protection Agency, LBNL-41543, March 1999.

Vreuls, H., De Groote, W., Bach, P., Schalburg, R., Dyhr-Mikkelsen, K., Bosseboeuf, D., Celi, O., Kim, J., Neij, L., Roosenburg, M. ( 2005). Evaluating energy efficiency policy measures \& DSM programmes - volume I : evaluation guidebook. Report for the IEA-DSM task IX, October 2005. Available at: http://www.ieadsm.org/Files/EXCO\%20File\%20Library/Key\%20Publications/Volume1Total.pdf. Accessed February 14, 2011.

Vreuls, H., Thomas, S., Broc, J.-S. (2009). General bottom-up data collection, monitoring, and calculation methods, Summary report. SenterNovem, Sittard, Wuppertal Institute, Wuppertal, ARMINES, Nantes

Wuppertal Institute on behalf of the EMEEES Consortium (2009). Measuring and reporting energy savings for the Energy Services Directive - how it can be done. Results and recommendations from the EMEEES project. Wuppertal Institute, Wuppertal 


\section{Appendix 1}

Table 4. Categories of calculation methods for unitary gross annual energy savings.

\begin{tabular}{|c|c|c|c|c|c|c|}
\hline \multirow{8}{*}{ 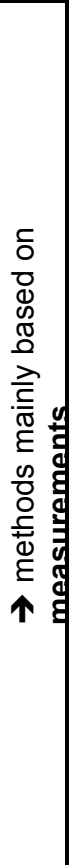 } & $\begin{array}{l}\text { Category of } \\
\text { method }\end{array}$ & $\begin{array}{c}\text { Main input data } \\
\text { (cf. ESD Annex IV(2)) }\end{array}$ & Type of formula & Options & $\begin{array}{l}\text { additional analysis / tools } \\
\text { required }\end{array}$ & $\begin{array}{c}\text { Characterisation of costs and data } \\
\text { collection }\end{array}$ \\
\hline & $\begin{array}{l}\text { 1) direct } \\
\text { measurement }\end{array}$ & end-use load data & Equation 1b & $\begin{array}{l}\text { a) without any } \\
\text { normalisation }\end{array}$ & & \multirow[t]{2}{*}{$\begin{array}{l}\text { can be costly; usually restricted to large } \\
\text { buildings or sites }\end{array}$} \\
\hline & & & {$[\approx I P M V P$ option B] } & $\begin{array}{l}\text { b) with } \\
\text { normalisations }\end{array}$ & $\begin{array}{l}\text { analysis of required } \\
\text { normalisation factors }\end{array}$ & \\
\hline & \multirow{4}{*}{$\begin{array}{l}\text { 2) billing } \\
\text { analysis } \\
\text { and }\end{array}$} & \multirow[t]{4}{*}{$\begin{array}{l}\text { energy bills or energy } \\
\text { sales data }\end{array}$} & \multirow{4}{*}{$\begin{array}{l}\text { Equation } 1 \mathrm{~b} \\
\text { unit = participant } \\
{[\approx I P M V P \text { option } C]}\end{array}$} & $\begin{array}{l}\text { a) without any } \\
\text { normalisation }\end{array}$ & $\begin{array}{l}\text { to be allowed only if } \\
\text { savings }>10 \%\end{array}$ & \multirow{4}{*}{$\begin{array}{l}\text { can be very costly to collect and analyse } \\
\text { particularly d); may be the only way of } \\
\text { evaluation for information campaigns }\end{array}$} \\
\hline & & & & $\begin{array}{l}\text { b) with } \\
\text { normalisations }\end{array}$ & $\begin{array}{l}\text { analysis of required } \\
\text { normalisation factors }\end{array}$ & \\
\hline & & & & $\begin{array}{l}\text { c) with control } \\
\text { group comparison }\end{array}$ & forming control groups & \\
\hline & & & & $\begin{array}{l}\text { d) other billing } \\
\text { analysis }\end{array}$ & $\begin{array}{l}\text { econometric or discrete } \\
\text { choice modelling }\end{array}$ & \\
\hline & $\begin{array}{l}\text { 3) enhanced } \\
\text { engineering } \\
\text { estimates (e.g. } \\
\text { calibrated } \\
\text { simulation) }\end{array}$ & $\begin{array}{l}\text { energy bills and/or } \\
\text { end-use metering } \\
\text { and/or equipment/ } \\
\text { building data from } \\
\text { inspection }\end{array}$ & $\begin{array}{l}\text { Equation } 1 \mathrm{a} \text { or } 1 \mathrm{~b} \\
\text { unit = participant or } \\
\text { equipment } \\
{[\approx I P M V P \text { option } D]}\end{array}$ & $\begin{array}{l}\text { variable level of } \\
\text { details }\end{array}$ & $\begin{array}{l}\text { simulation tool calibrated } \\
\text { with billing or metering data }\end{array}$ & $\begin{array}{l}\text { can be costly; however, if an energy } \\
\text { audit is done anyway, small extra cost of } \\
\text { monitoring results }\end{array}$ \\
\hline 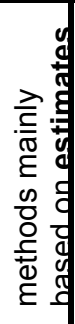 & $\begin{array}{l}\text { 4) mixed } \\
\text { deemed and ex- } \\
\text { post estimate }\end{array}$ & $\begin{array}{l}\text { engineering estimates } \\
\text { and measure-specific } \\
\text { data (e.g., from } \\
\text { equipment and } \\
\text { appliance sales data, } \\
\text { inspection of samples, } \\
\text { monitoring of } \\
\text { equipment purchased } \\
\text { by participants) }\end{array}$ & $\begin{array}{l}\text { Equation } 1 \mathrm{a} \text { or } 1 \mathrm{~b} \\
\text { unit = equipment } \\
{[\approx I P M V P \text { option } D]}\end{array}$ & $\begin{array}{l}\text { combinations of } \\
\text { reference values } \\
\text { and measure- } \\
\text { specific values }\end{array}$ & $\begin{array}{l}\text { analysis of parameters to } \\
\text { be included in calculations } \\
\text {; definition of reference ex- } \\
\text { ante values for some of } \\
\text { these parameters }\end{array}$ & $\begin{array}{l}\text { costs depend on level of accuracy and } \\
\text { gross-to-net correction required; } \\
\text { monitoring usually straightforward }\end{array}$ \\
\hline
\end{tabular}




\begin{tabular}{|l|l|l|l|l|l|l|}
\hline $\begin{array}{l}\text { 5) deemed } \\
\text { savings }\end{array}$ & $\begin{array}{l}\text { engineering estimates } \\
\text { or sample } \\
\text { measurements (e.g., } \\
\text { from equipment and } \\
\text { appliance sales data, } \\
\text { inspection of samples } \\
\text { before implementation } \\
\text { of the energy } \\
\text { efficiency } \\
\text { improvement } \\
\text { measure) }\end{array}$ & $\begin{array}{l}\text { Equation 1a or 1b } \\
\text { unit = equipment }\end{array}$ & $\begin{array}{l}\text { method 5) is } \\
\text { actually an option } \\
\text { of method 4) (all } \\
\text { ex-ante) }\end{array}$ & $\begin{array}{l}\text { analysis of parameters to } \\
\text { be included in calculations } \\
\text { idefinition of reference ex- } \\
\text { ante values for all of these } \\
\text { parameters }\end{array}$ & $\begin{array}{l}\text { costs can be quite low, monitoring of } \\
\text { number of measures and savings per } \\
\text { measure may be combined with }\end{array}$ \\
"anyway" contacts \\
\end{tabular}

